Check for updates

Cite this: RSC Adv., 2018, 8, 18456

Received 12th January 2018

Accepted 12th April 2018

DOI: $10.1039 / c 8 \mathrm{ra00356d}$

rsc.li/rsc-advances

\section{Recent advances in sulfur-nitrogen bond formation via cross-dehydrogenative coupling reactions}

\author{
Fatemeh Alsadat Hosseini Nasab, ${ }^{a}$ Leila Zare Fekri, ${ }^{\mathrm{b}}$ Aazam Monfared, ${ }^{\mathrm{b}}$ \\ Akram Hosseinian ${ }^{\star c}$ and Esmail Vessally (D) ${ }^{b}$
}

This focus-review surveys literature methods for the construction of sulfur-nitrogen bonds through crossdehydrogenative coupling reactions between thiols and $\mathrm{N}-\mathrm{H}$ compounds with a particular emphasis on the mechanistic aspects of the reactions. The literature has been surveyed until the end of 2017.

\section{Introduction}

Needless to say, organosulfur compounds play a very important role in various fields such as organic synthesis, materials science, agriculture, and medicinal chemistry ${ }^{1-4}$ Among them, compounds bearing sulfur-nitrogen bonds are important building blocks in a variety of biologically active substances. For instance, sultiame 1 (Fig. 1) with brand name Ospolot is a synthetic sulfa-based drug marketed worldwide for the treatment of epilepsy. ${ }^{5,6}$ The drug works by reducing the activity of carbonic anhydrase, an enzyme responsible for catalyzing the interconversion of carbon dioxide and water to carbonic acid by using a metal hydroxide nucleophilic mechanism. ${ }^{7}$ Topiramate

${ }^{a}$ Department of Chemistry, Hormozgan University, P. O. Box 3995, Bandar Abbas, Iran Iran

${ }^{c}$ Department of Engineering Science, College of Engineering, University of Tehran, $P . O$. Box 11365-4563, Tehran, Iran. E-mail: hoseinian@ut.ac.ir ${ }^{b}$ Department of Chemistry, Payame Noor University, P. O. Box 19395-1697, Tehran,

2 with trade name Topamax is a promising anticonvulsant medicine available in a number of countries worldwide. The drug is also used for migraine prevention in adults. ${ }^{8}$ Folpet 3 is a fungicide used for broad-spectrum control of fungal pathogens. ${ }^{9}$ Sulfoxaflor 4 is an insecticide with a sulfoximine motif, this compound is very active against a wide range of sap-feeding insect pests and widely used around the world. ${ }^{10}$ Thus, construction of biologically and synthetically important sulfurnitrogen bonds is one of the essential transformations in organic synthesis. Conventional methods to achieve such linkages involve cross-coupling of S-halo compounds and $\mathrm{N}-\mathrm{H}$ compounds in the presence of strong bases ${ }^{11}$ or metal-catalyzed cross-coupling reactions between $\mathrm{N}$-halogenated compounds and thiols/disulfides. ${ }^{12}$ However, the limited availability of commercial starting materials, the formation of undesired byproducts and/or harsh reaction conditions are the main drawbacks of these methods. Therefore, the search for novel straightforward and eco-friendly green approaches to the

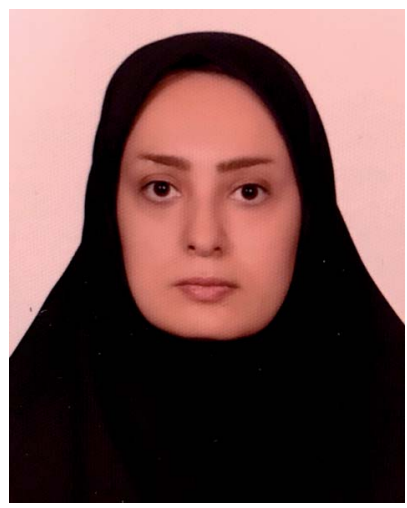

Leila Zare Fekri was born in

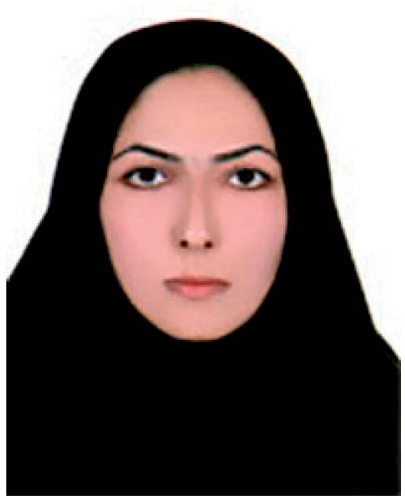

Fatemeh Alsadat Hosseini Nasab was born in Sirjan, Kerman, Iran, in 1980. She received her B.S. degree in Pure Chemistry from University of Shahid Bahonar, Kerman, Iran, and her M.S. degree in Organic Chemistry from Shahid Bahonar University, Kerman, Iran, in 2006 under the supervision of Dr M. Eslami. Now she is working at Hormozgan University of Bandar Abbas, as an Instructor. Her research interests include organic synthesis and new nanochemistry.
Rasht, Iran, in 1980. She received her B.Sc. degree in Pure Chemistry from Guilan University, Rasht, Iran, and her M.Sc. degree in Organic Chemistry from Guilan University, Rasht, Iran, in 2006 under the supervision of Prof. N. Mahmoodi. She received her Ph.D. degree in 2010 under the supervision $N$. Mahmoodi in Guilan University, Rasht, Iran. Now she is working at Payame Noor University of Guilan as Assistant Professor. Her research interests include organic synthesis, green chemistry, onepot reaction, new nanochemistry and calculated chemistry. 
synthesis of sulfur-nitrogen bond-containing compounds remains a challenge.

Metal-catalyzed and metal-free cross-coupling reactions have been shown to be one of the most powerful methods for the construction of $\mathrm{C}-\mathrm{C}, \mathrm{C}-\mathrm{X}$, and $\mathrm{X}-\mathrm{X}^{\prime}$ bonds $\left(\mathrm{X}, \mathrm{X}^{\prime}=\right.$ heteroatom) ${ }^{13-15}$ Cross-dehydrogenative coupling (often called oxidative coupling) reactions are green and sustainable alternatives to traditional coupling procedures which rely on the use of two unmodified coupling partners. ${ }^{15,16}$ Indeed, in these reactions the relatively inactive $\mathrm{C}(\mathrm{X})-\mathrm{H}$ bonds can be treated as a functional group, similar to the traditionally used $\mathrm{C}(\mathrm{X})$-(pseudo) halide bonds. Along this line, recently, oxidative coupling of thiols and $\mathrm{N}-\mathrm{H}$ compounds has gained a lot of attention because of the atom-economic and waste-minimization characters. The most obvious benefit of this route for construction of sulfur-nitrogen bond is that there is no need for preparation and isolation of halogenated reagents, thus improving pot, atom, and step economy. An overview of this emerging area is

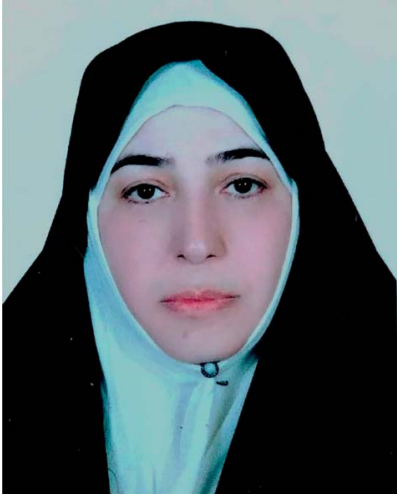

Aazam Monfared was born in Tehran, Iran, in 1965. She received her B.S. degree in Pure Chemistry from University of Shahid Beheshti, Tehran, Iran, and her M.S. degree in Organic Chemistry from Shahid Beheshti University, Tehran, Iran, in 1991 under the supervision of Prof. A. Rustaiyan. She received her Ph.D. degree in 1999 under the supervision of Prof. A. Rustaiyan in Shahid Beheshti University, Tehran, Iran. Now, she is working at Payame Noor University of Tehran as Associate Professor. Her research interests include organic synthesis, phytochemistry, drug synthesis, nano chemistry, methodologies and theoretical chemistry.

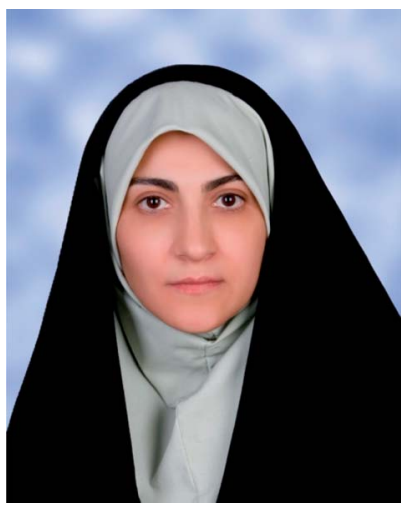

Akram Hosseinian was born in Ahar, Iran, in 1973. She received her B.S. degree in Pure Chemistry from University of Tehran, Iran, and her M.S. degree in Inorganic Chemistry from Tarbiat Modares University, Tehran, Iran, in 2000 under the supervision of Prof. A. R. Mahjoub. She completed her Ph.D. degree in 2007 under the supervision of Prof. A. R. Mahjoub. Now she is working at University of Tehran as Associate Professor. Her research interests include inorganic and organic synthesis, new methodologies in nano material synthesis. presented in this mini-review with a particular emphasis on the mechanistic aspects of the reactions. It is noted that the reactions were classified according to the type of products (Fig. 2). Literature has been surveyed until the end of 2017.

\section{Synthesis of sulfenamides}

In 2010, N. Taniguchi reported the first example of $\mathrm{Cu}(\mathrm{I})$-catalyzed cross-dehydrogenative coupling of aryl thiols 5 with amines 6 in the presence of $\mathrm{Cu}(\mathrm{I}) / \mathrm{bpy}\left(2,2^{\prime}\right.$-bipyridine) combination as a catalytic system in air as the terminal oxidant, which allows for preparation of a broad range of sulfenamides 7 in moderate to excellent yields (Scheme 1). ${ }^{17 \boldsymbol{a}}$ The reaction is noteworthy in that both primary and secondary amines are tolerated. The results demonstrated that aliphatic amines generally gave higher yields than arylamines. It should be mentioned that the electronic character of the substituents in aryl thiols had a strong effect on the facility of reaction. While electron-donating, mild electron-withdrawing and unsubstituted thiophenol gave the desired products in good yields, the strongly electron-withdrawing nitro-substituted thiophenol failed to afford the product. Interestingly, when the reaction was carried out under the oxygen atmosphere, the corresponding sulfonamides were obtained in moderate to high yields. Furthermore, the author observed that using $\mathrm{PdCl}_{2} / \mathrm{CuI}$ binary catalyst, the reaction of aryl thiols with primary amines in air selectively afforded sulfinamides derivatives. The author proposed mechanism for the formation of sulfenamides is shown in Scheme 2. A possible process for the formation of sulfenamides 7 should involve the formation of intermediate $\mathbf{B}$ via oxidative addition of starting aryl thiol $\mathbf{5}$ with copper catalyst A, followed by oxidation of this intermediate with air oxygen to give the intermediate $\mathbf{C}$, which after reaction with amine $\mathbf{6}$ delivers the intermediate $\mathbf{D}$. Finally, reductive elimination of intermediate D affords the desired product 7 (cycle A, Scheme 2). In another possibility, oxidative homocoupling of thiol 5 can happen to give the disulfide $\mathbf{E}$, which after reaction with amine

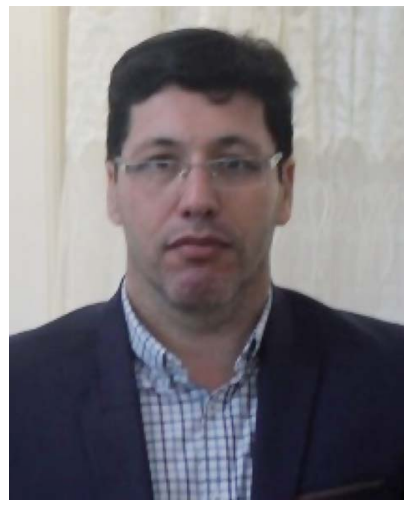

Esmail Vessally was born in Sharabiyan, Sarab, Iran, in 1973. He received his B.S. degree in Pure Chemistry from University of Tabriz, Tabriz, Iran, and his M.S. degree in Organic Chemistry from Tehran University, Tehran, Iran, in 1999 under the supervision of Prof. H. Pirelahi. He completed his Ph.D. degree in 2005 under the supervision of Prof. M. Z. Kassaee. Now he is working at Payame Noor University as full Professor of Organic Chemistry. His research interests include theoretical organic chemistry, new methodologies in organic synthesis and spectral studies of organic compounds. 


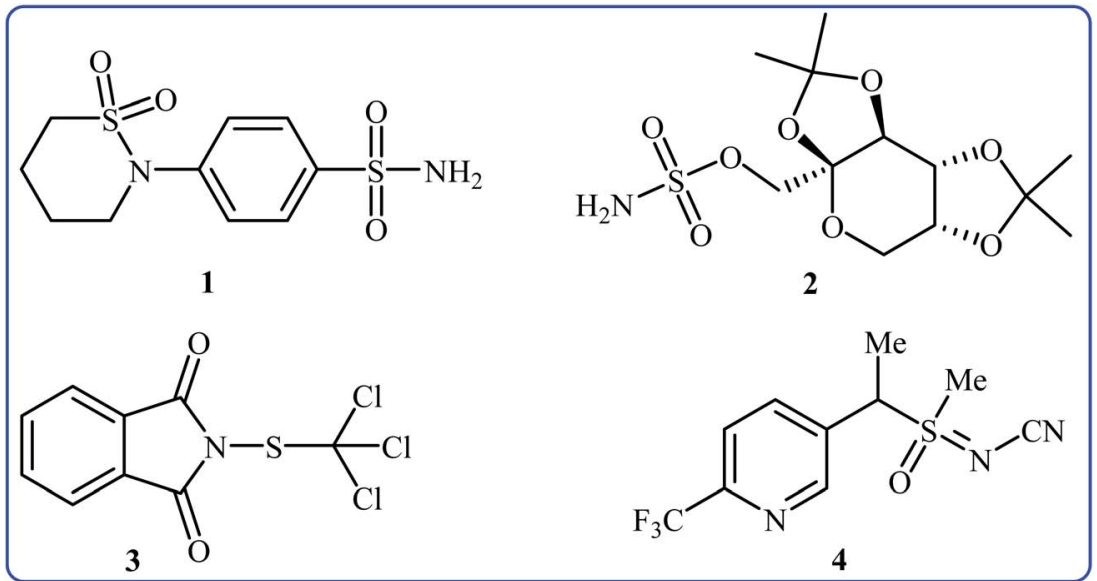

Fig. 1 Selected examples of biologically active sulfur-nitrogen bond-containing organosulfur compounds.

6 affords sulfenamide 7 with the generation of intermediate $\mathbf{C}$ (cycle B, Scheme 2). ${ }^{17}$

Four years later, the group of Wacharasindhu studied the possibility of synthesizing heterocyclic sulfenamides $\mathbf{1 0}$ through hypervalent iodine-catalyzed cross-dehydrogenative coupling of $\mathrm{N}$ heterocyclic thiols 8 with amines $9 .^{18}$ Thus, the careful analysis of the reaction optimization results showed that the optimum condition for this cross-coupling reaction was the addition of DBU ( 2 equiv.) and amine ( 2 equiv.) at $0{ }^{\circ} \mathrm{C}$, to a solution of DIB (1.1 equiv.) and thiol (1.0 equiv.) in ${ }^{\mathrm{i}} \mathrm{PrOH}$. The optimized protocol tolerated a variety of N-heterocyclic thiols, such as 2-mercaptopyridine, 4-mercaptopyridine, 2-mercaptopyrimidine, 2-mercaptobenzothiazol, and 2-mercaptoquinoline, and provided heterocyclic sulfenamides 10 in moderate to high yields with a mixture of corresponding disulfides $\mathbf{1 1}$ (Scheme 3). In this study, the authors reported some limitations in their methodology, since considerable difficulties were found when they attempted to react the sterically hindered tert-butylamine and the less nucleophilic aniline. In these cases, they observed only disulfide products with no formation of sulfenamide product. The mechanism shown in Scheme 4 was proposed for the formation of sulfonamides $\mathbf{1 0 .}$

Very recently, Yuan's research team developed an efficient synthesis of 2-benzothiazole-sulfenamides 14 via direct aerobic oxidative amination of 2-mercaptobenzothiazole 12 under metal-free conditions. ${ }^{19}$ In this transformation, 2,2,6,6(tetramethylpiperidin-1-yl)oxyl (TEMPO) was utilized as the catalyst and $\mathrm{O}_{2}$ as the oxidant without any co-oxidant. Solvent has a dramatic role in the reaction and among the various solvents such as MeOH, EtOH, DCM, DCE, DMF, MeCN, EtOAc, toluene, acetone, chlorobenzene, ethylbenzene; MeCN was the

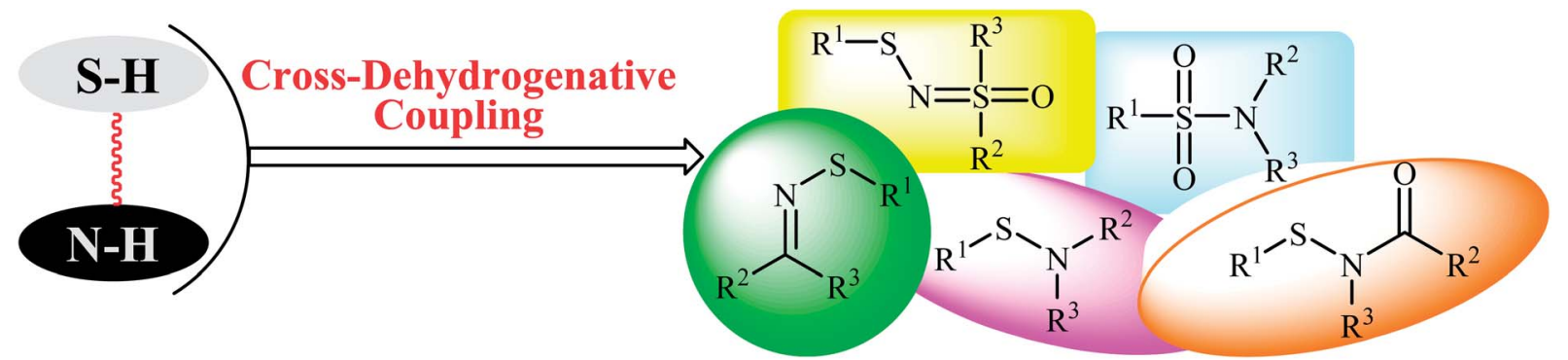

Fig. 2 Synthesis of a variety of sulfur-nitrogen bond-containing organosulfur compounds via cross-dehydrogenative coupling reactions.<smiles>[R][X]c1ccccc1</smiles>

5

$\mathrm{R}^{1}=\mathrm{H}, 4-\mathrm{Me}, 4-\mathrm{OMe}, 4-\mathrm{Cl}, 2-\mathrm{Me}, 2-\mathrm{Br}$

$\mathrm{R}^{2}=\mathrm{H}, \mathrm{Me}, \mathrm{Et}$

$\mathrm{R}^{3}=\mathrm{Et},{ }^{i} \mathrm{Pr},{ }^{n} \mathrm{Bu},{ }^{t} \mathrm{Bu}, \mathrm{Ph}, 4-\mathrm{Me}-\mathrm{C}_{6} \mathrm{H}_{4}, 4-\mathrm{Cl}-\mathrm{C}_{6} \mathrm{H}_{4}$

$\mathrm{R}^{2}+\mathrm{R}^{3}=-\left(\mathrm{CH}_{2}\right)_{5}-$

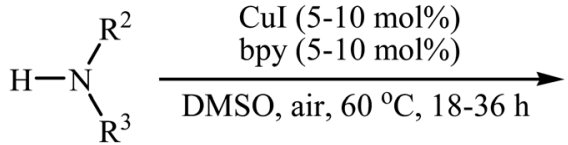

6<smiles>[R]N([R])SC1=CC#[R]=CC=C1</smiles>

13 examples (40-90\%)

(average yield: 75\%)

Scheme $1 \mathrm{Cu}(\mathrm{I})$-catalyzed S-N coupling of aryl thiols 5 with amines 6 . 


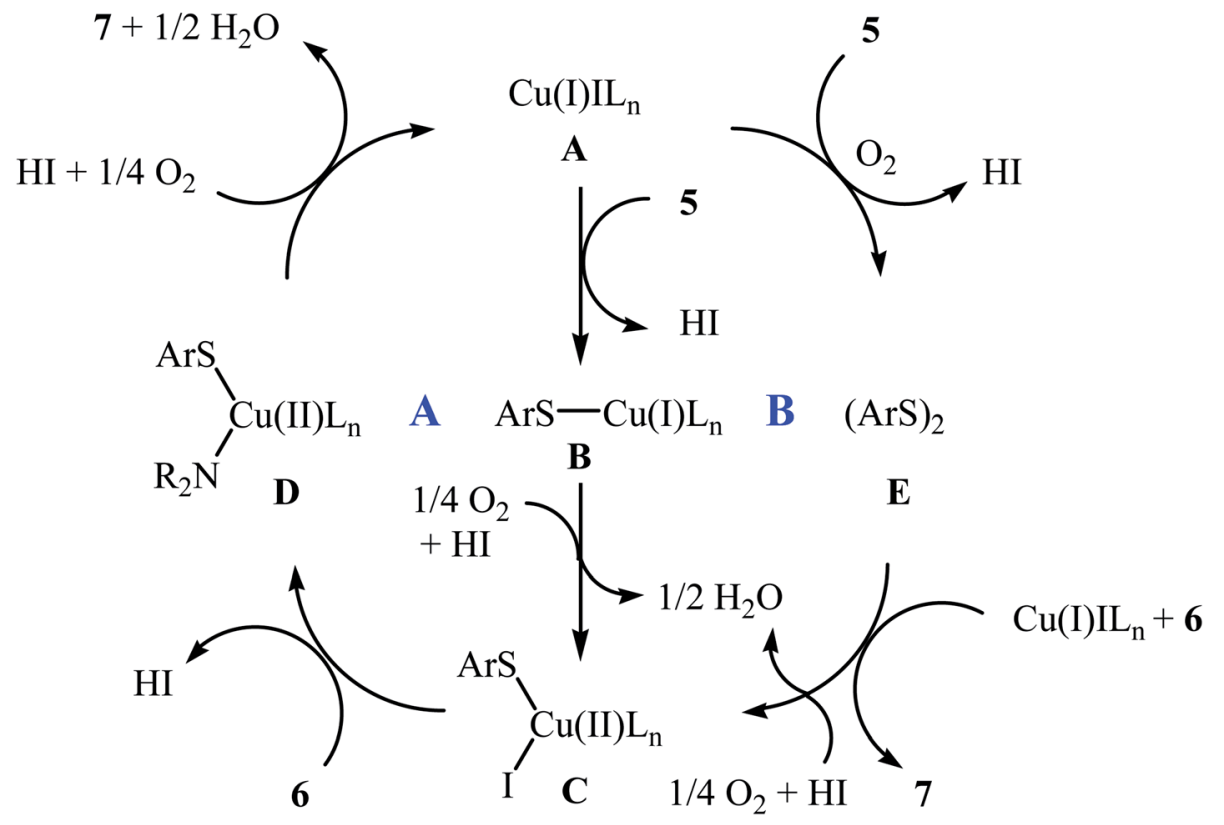

Scheme 2 Mechanistic proposal for the reaction in Scheme 1.

most effective solvent. Various aliphatic amines $\mathbf{1 3}$ were reacted well under the optimized reaction conditions to produce the target sulfonamides $\mathbf{1 4}$ in good to almost quantitative yields (Scheme 5). A plausible mechanism was proposed for this transformation (Scheme 6). It consists of the following key steps: (i) hydrogen-transfer reaction between a thiol $\mathbf{1 2}$ and TEMPO forms the thiyl radical A and TEMPOH; (ii) oxidation of TEMPOH by $\mathrm{O}_{2}$ regenerates TEMPO; (iii) coupling of two thiyl

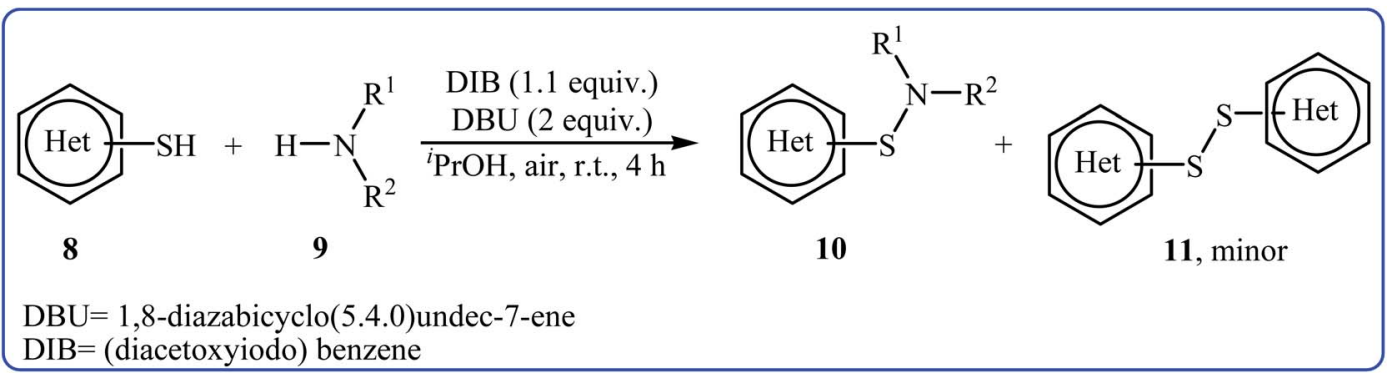<smiles>[R]NSc1ccccn1</smiles>

10a, $\mathrm{R}={ }^{n} \mathrm{Bu} ;(90 \%)$

10b, $\mathrm{R}=\mathrm{Bn} ;(65 \%)$

10c, $\mathrm{R}={ }^{c} \mathrm{Hex} ;(54 \%)$

10d, $\mathrm{R}=\mathrm{CH}_{2} \mathrm{CH}_{2} \mathrm{OH} ;(43 \%)$

10e, $\mathrm{R}=\mathrm{CH}_{2} \mathrm{CH}(\mathrm{OEt})_{2} ;(57 \%)$<smiles>[X]CCN(CC[Te])Sc1ccccn1</smiles>

10f, $\mathrm{n}=0, \mathrm{X}=\mathrm{CH}_{2} ;(60 \%)$

$10 \mathrm{~g}, \mathrm{n}=1, \mathrm{X}=\mathrm{CH}_{2} ;(61 \%)$

10h, $\mathrm{n}=1, \mathrm{X}=\mathrm{O} ;(59 \%)$<smiles>[R]NSc1ccncc1</smiles>

10i, $\mathrm{R}={ }^{n} \mathrm{Bu} ;(77 \%)$

10j, $\mathrm{R}=\mathrm{Bn} ;(51 \%)$

10k, R $={ }^{c} \mathrm{Hex} ;(67 \%)$

10l, $\mathrm{R}=\mathrm{CH}_{2} \mathrm{CH}_{2} \mathrm{OH} ;(57 \%)$

$10 \mathrm{~m}, \mathrm{R}=\mathrm{CH}_{2} \mathrm{CH}(\mathrm{OEt})_{2} ;(62 \%)$<smiles>[X]CCN(C)Sc1ccccn1</smiles>

10n, $\mathrm{n}=0, \mathrm{X}=\mathrm{CH}_{2} ;(68 \%)$

10o, $\mathrm{n}=1, \mathrm{X}=\mathrm{CH}_{2} ;(63 \%)$

10p, $n=1, X=O ;(64 \%)$<smiles>c1ccc(CNSc2ccc3ccccc3n2)cc1</smiles>

10q, $(64 \%)$<smiles>c1ccc(CNSc2nc3ccccc3s2)cc1</smiles>

10r, $(73 \%)$<smiles>[Y]c1c[X]c(SNCc2ccccc2)nc1</smiles>

10s, $X=N, Y=H ;(72 \%)$

10t, $\mathrm{X}=\mathrm{CH}, \mathrm{Y}=\mathrm{Br} ;(67 \%)$

Scheme 3 Synthesis of sulfenamides 10 through hypervalent iodine-catalyzed cross-dehydrogenative coupling of N-heterocyclic thiols 8 with amines 9 . 


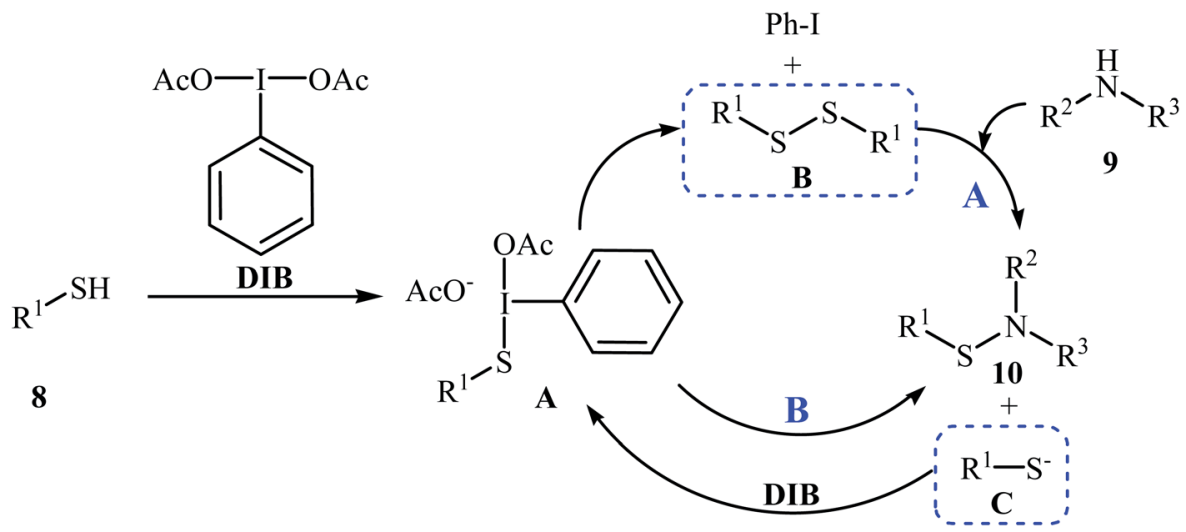

Scheme 4 Mechanistic proposal for the formation of 10.

radicals A gives disulfide $\mathbf{B}$; and (iv) reaction of disulfide $\mathbf{B}$ and amine $\mathbf{1 3}$ affords the expected sulfonamide $\mathbf{1 4}$ and mercaptide ion $\mathbf{C}$, which can be oxidized in situ to regenerate the disulfide $\mathbf{B}$.

With the aim of designing a greener procedure to sulfenamides via aerobic oxidative coupling of thiols with amines, the same research group was able to demonstrate that a range of 2benzothiazole-sulfenamides $\mathbf{1 6}$ could be obtained from the reaction of 2-mercaptobenzothiazole $\mathbf{1 2}$ with various aromatic and aliphatic amines $\mathbf{1 5}$ in the water media, employing $\mathrm{Co}$ (phcy) $\left(\mathrm{SO}_{3} \mathrm{Na}\right)_{4}$ as a catalyst under $\mathrm{O}_{2}$ atmosphere (Scheme 7). ${ }^{20}$ Beside good yields, broad substrate scope, scale-up ability, and easy work-up were the advantages, mentioned for this green synthetic approach. According to the author proposed mechanism, the reaction proceeds along the similar mechanistic pathway that described in Scheme 6. The authors also nicely showed the application of this environment-friendly catalytic system for the oxidative homocoupling of a variety of aromatic and aliphatic thiols to the construction of corresponding disulfides in excellent to almost quantitative yields.

\section{Synthesis of $N$-acylsulfenamides}

In 2006, Tellitu and Domínguez along with co-workers synthesized a library of biologically important $N$-substituted benzo[d] isothiazol-3(2H)-one derivatives 18 via the hypervalent iodine reagent [phenyliodine(III)-bis(trifluoroacetate)] (PIFA) mediated

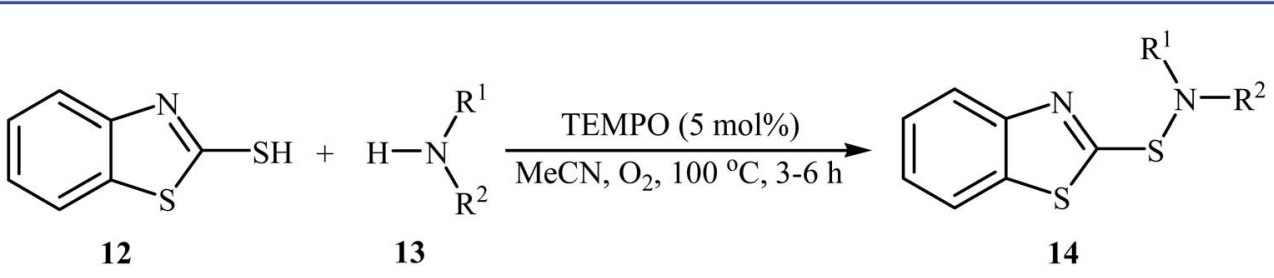

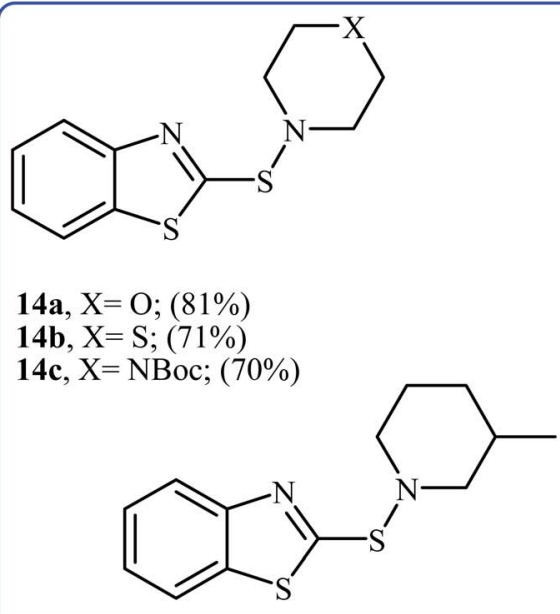

14h, $(91 \%)$<smiles>[R]NSc1nc2ccccc2s1</smiles>

14d, $\mathrm{R}={ }^{t} \mathrm{Bu} ;(99 \%)$

14e, $\mathrm{R}={ }^{c} \mathrm{Hex} ;(88 \%)$

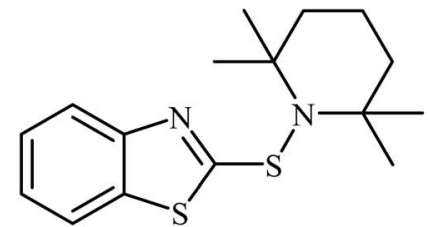<smiles>[R]N([R])Sc1nc2ccccc2s1</smiles>

14f, $\mathrm{R}=\mathrm{Et} ;(67 \%)$

14g, $\mathrm{R}={ }^{i} \operatorname{Pr} ;(65 \%)$

$14 i,(56 \%)$

Scheme 5 Yuan's synthesis of 2-benzothiazole-sulfenamides 14. 


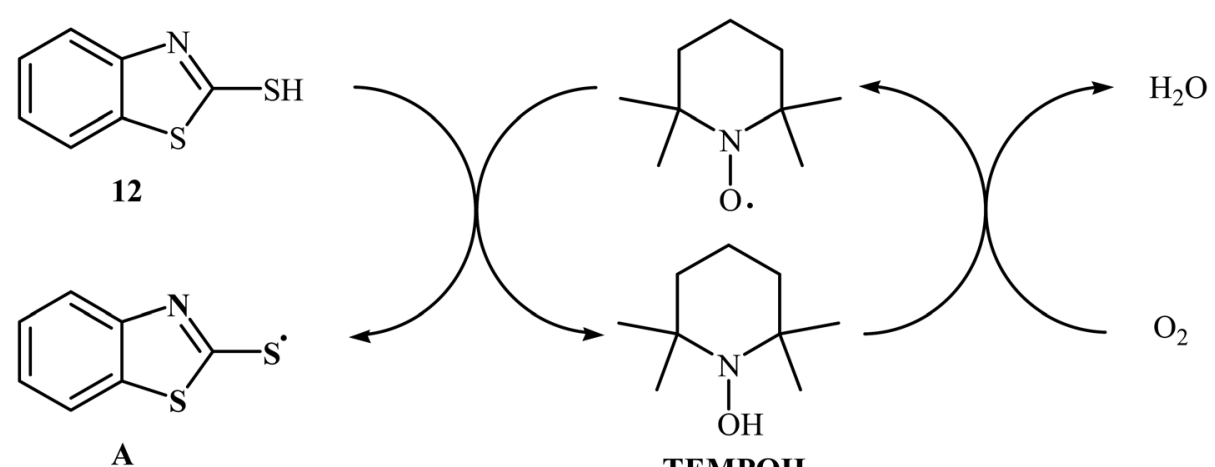

A

TEMPOH
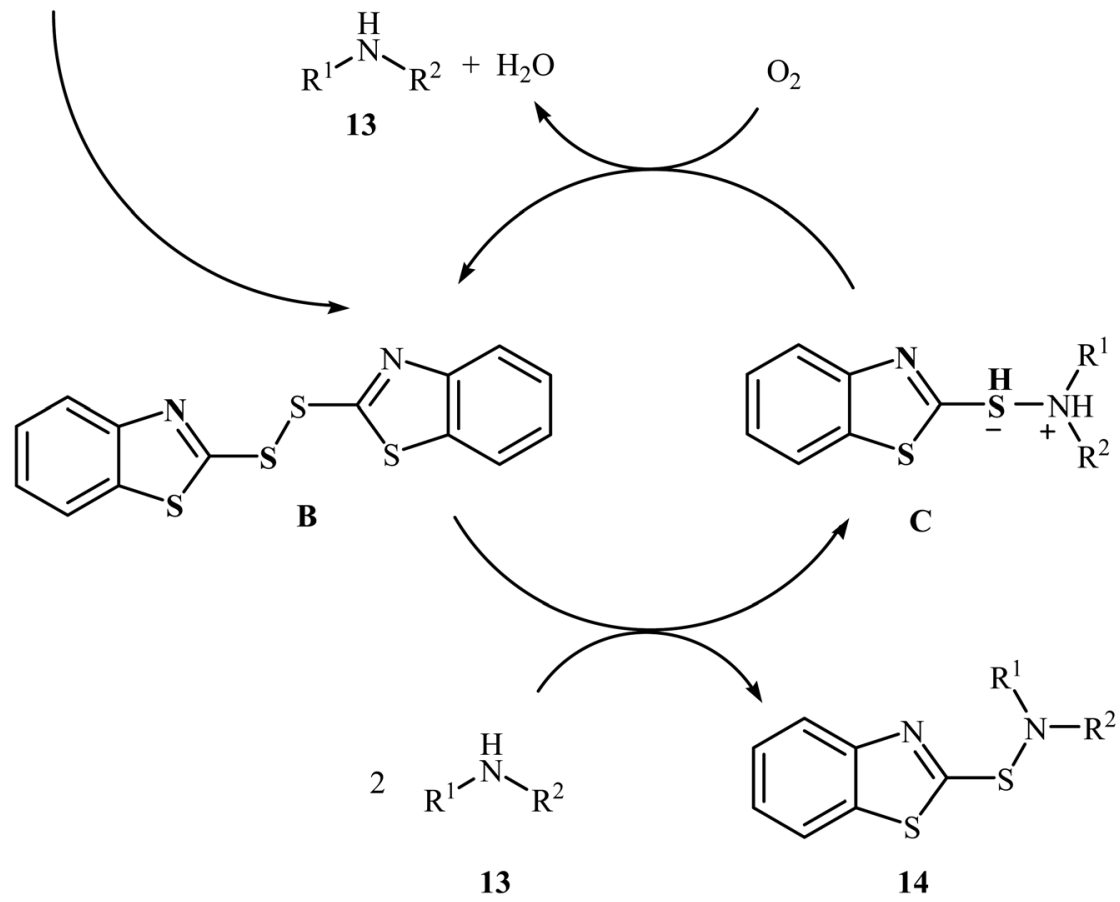

Scheme 6 Mechanism that accounts for the formation of 2-benzothiazole-sulfenamides 14.

intramolecular oxidative cyclization of corresponding $\mathrm{N}$ substituted 2-mercapto-benzamides 17 employing TFA as an additive in DCM at $0{ }^{\circ} \mathrm{C}^{21}$ As shown in Scheme 8 the reaction showed good functional group tolerance, including bromo, iodo, and methoxy functionalities and gave corresponding cyclic products in moderate to good yields. However, $\mathrm{N}$-allyl substituted 2-mercapto-benzamide failed to participate in this cyclization. It is noted that starting 2-mercapto-benzamides can be easily synthesized from the reaction of commercially available methyl thiosalicylate with primary amines. According to the authors proposed mechanism, the key step of the reaction involves the formation of a reactive $N$-acylnitrenium ion intermediate A. Shortly afterwards, the group of Cosford employed this interesting synthetic approach to access a series of novel drug-like benzoisothiazolones with significant inhibitory activities against phosphomannose isomerase (PMI), an enzyme that converts mannose-6-phosphate (Man-6-P) into fructose-6phosphate (Fru-6-P). ${ }^{22}$

Inspired by these works, Wang and co-workers also showed that $N$-substituted benzoisothiazolones 20 were successfully formed from corresponding 2-mercapto-benzamides 19 in a simple process employing commercially available and inexpensive CuI as a catalyst and oxygen as an environmentally benign oxidant, in DMF as solvent and at $70{ }^{\circ} \mathrm{C} .{ }^{23}$ This method afforded the desired benzoisothiazolones in high to quantitative yields with various alkyl, aryl, and allyl substituents on nitrogen atom (Scheme 9). The process can also be scaled up to provide multigram quantities of the target compound without obvious loss in the yield or outcome. The authors nicely applied this methodology to the high yielding synthesis of piroxicam 23, a nonsteroidal anti-inflammatory drug, precursor (Scheme 10). The following mechanism has been proposed to explain the formation of compounds $\mathbf{2 0}$ (Scheme 11). The complex $\mathbf{A}$ is first formed by the coordination of 2-mercapto-benzamide 19 to a copper atom. A subsequent oxidative formation of a $\mathrm{Cu}-\mathrm{S}$ bond via the elimination of $\mathrm{H}_{2} \mathrm{O}$ provides the intermediate $\mathbf{B}$, which then undergoes oxidative formation of a $\mathrm{Cu}-\mathrm{N}$ bond via the elimination of $\mathrm{H}_{2} \mathrm{O}_{2}$ to form intermediate $\mathbf{C}$ that, after reductive elimination affords the final product 20 . In their subsequent study, they reinvestigated the same reaction by 

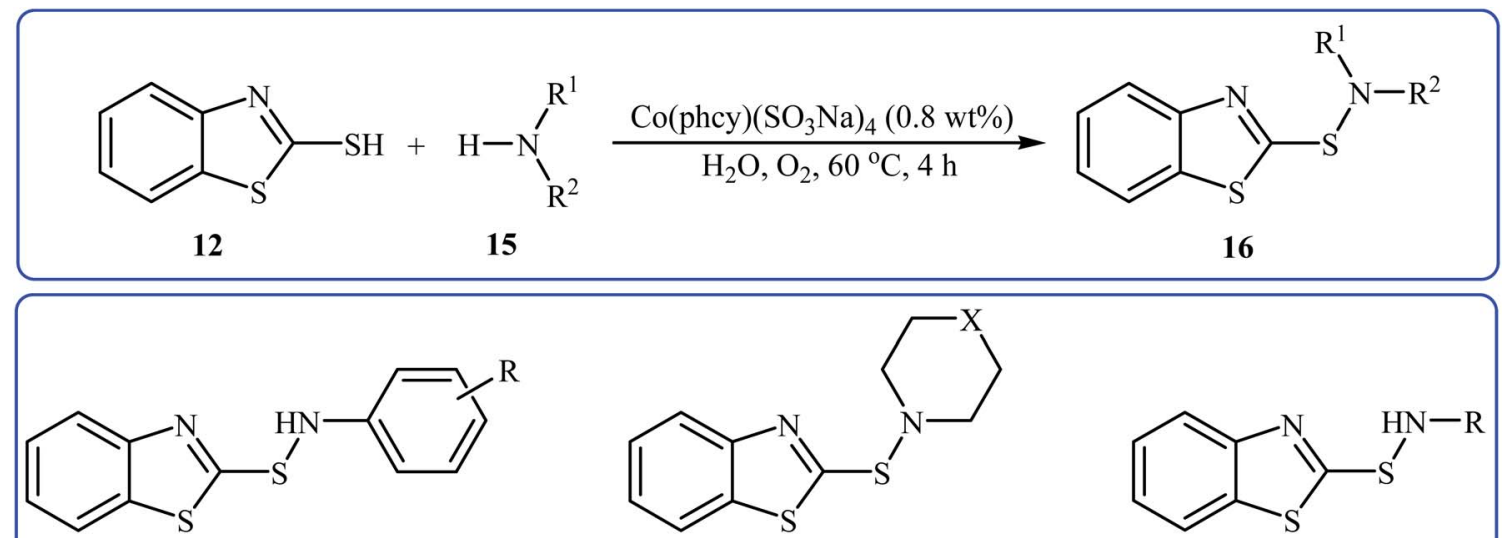

16a, $\mathrm{R}=\mathrm{H} ;(59 \%)$

16b, $\mathrm{R}=4-\mathrm{Me} ;(67 \%)$

16c, $\mathrm{R}=4-\mathrm{Cl} ;(47 \%)$

16d, $\mathrm{R}=4-\mathrm{Br} ;(53 \%)$

16e, $\mathrm{R}=3-\mathrm{Me} ;(65 \%)$

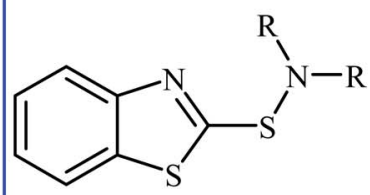

16n, $\mathrm{R}=\mathrm{Et}$; $(76 \%)$

16o, $\mathrm{R}={ }^{i} \mathrm{Pr} ;(71 \%)$

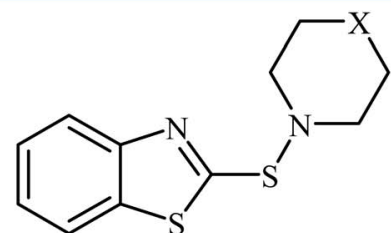

16f, $X=O ;(78 \%)$

16g, $X=S ;(96 \%)$

16h, $X=$ NBoc; $(91 \%)$

16i, $\mathrm{X}=-\mathrm{COCH}_{2} \mathrm{CH}_{2} \mathrm{O} ;(81 \%)$<smiles>[R]NSc1nc2ccccc2s1</smiles>

16j, $\mathrm{R}={ }^{n} \operatorname{Pr} ;(81 \%)$

16k, $\mathrm{R}={ }^{t} \mathrm{Bu} ;(95 \%)$

16l, $\mathrm{R}={ }^{c} \mathrm{Hex} ;(90 \%)$

16m, $\mathrm{R}=\mathrm{Bn}$; $(92 \%)$

Scheme $7 \mathrm{Co}\left(\right.$ phcy) $\left(\mathrm{SO}_{3} \mathrm{Na}\right)_{4}$ catalyzed synthesis of 2-benzothiazole-sulfenamides 16 reported by Yuan. ${ }^{20}$

using $\mathrm{KBr}$ as a green catalyst under air condition. A diverse range of benzo[ $[d]$ isothiazol-3(2H)-ones (14 examples) in very impressive yields (up to 95\%) with good functional group tolerance were obtained. ${ }^{24}$
The first copper-catalyzed intermolecular crossdehydrogenative coupling reaction between thiols and amides was reported by Jang's group in $2015 .{ }^{25}$ In this study, various copper salts (e.g., CuI, $\mathrm{CuBr}, \mathrm{CuOAc}$, and $\left.\mathrm{CuBr}_{2}\right)$ and base (e.g.,<smiles>[R]NC(=O)c1ccccc1S</smiles><smiles>[R]c1ccc(-n2sc3ccccc3c2=O)cc1</smiles>

18a, $\mathrm{R}=\mathrm{H} ;(71 \%)$

18b, R= 4-Et; $(66 \%)$

18c, $\mathrm{R}=4-\mathrm{OMe} ;(78 \%)$

18d, $R=2-I ;(64 \%)$

18e, $\mathrm{R}=2-\mathrm{Br}-4-\mathrm{Me} ;(67 \%)$<smiles>O=c1c2ccccc2sn1-c1cccc2ccccc12</smiles><smiles>COc1ccc(-n2sc3ccccc3c2=O)cn1</smiles>

$18 \mathrm{~g},(70 \%)$<smiles>[R]n1sc2ccccc2c1=O</smiles>

18h, R= Me; $(60 \%)$

$18 \mathrm{i}, \mathrm{R}=\mathrm{Bn} ;(60 \%)$

Scheme 8 Tellitu's synthesis of benzo[d] isothiazol-3(2H)-one derivatives 18 


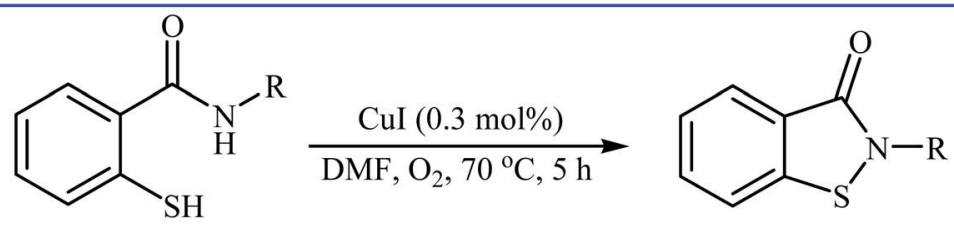

19

20<smiles>[R]c1ccc(-n2sc3ccccc3c2=O)cc1</smiles>

20a, $\mathrm{R}=4-\mathrm{Me} ;(95 \%)$

20b, $\mathrm{R}=4-\mathrm{OMe} ;(95 \%)$

20i, $(95 \%)$<smiles>O=c1c2ccccc2sn1-c1cccnc1</smiles>

20c, $R=4-F$; (95\%)

20d, $\mathrm{R}=4-\mathrm{CN} ;(99 \%)$

20e, $\mathrm{R}=2-\mathrm{I}$; $(83 \%)$

20f, $\mathrm{R}=2-\mathrm{Br}$; $(98 \%)$

20g, R= 2-Br-4-Me; (97\%)

20h, $\mathrm{R}=2,6-\mathrm{Me}_{2} ;(98 \%)$<smiles>O=c1c2ccccc2sn1-c1cccc2ccccc12</smiles>

20j, (95\%)

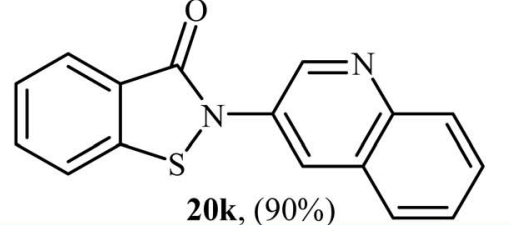<smiles>[R]n1sc2ccccc2c1=O</smiles>

201, $\mathrm{R}={ }^{t} \mathrm{Bu}$; (92\%)

20m, $\mathrm{R}={ }^{n} \mathrm{C}_{6} \mathrm{H}_{13} ;(99 \%)$

20n, $\mathrm{R}=$ vinyl; (95\%)

Scheme $9 \mathrm{Cu}(\mathrm{I})$-catalyzed synthesis of benzoisothiazolones 20 through intramolecular $\mathrm{S}-\mathrm{N}$ cross-dehydrogenative coupling of 2-mercaptobenzamides 19

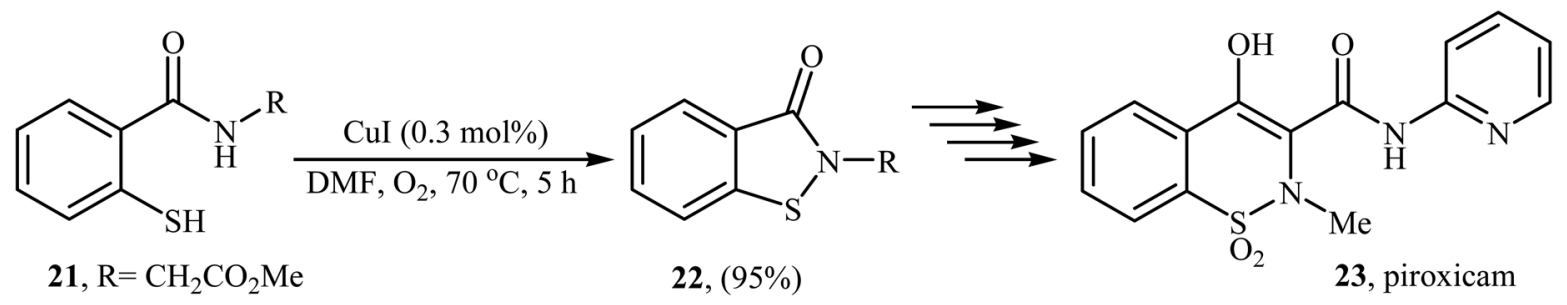

Scheme 10 Wang's synthesis of piroxicam 23.

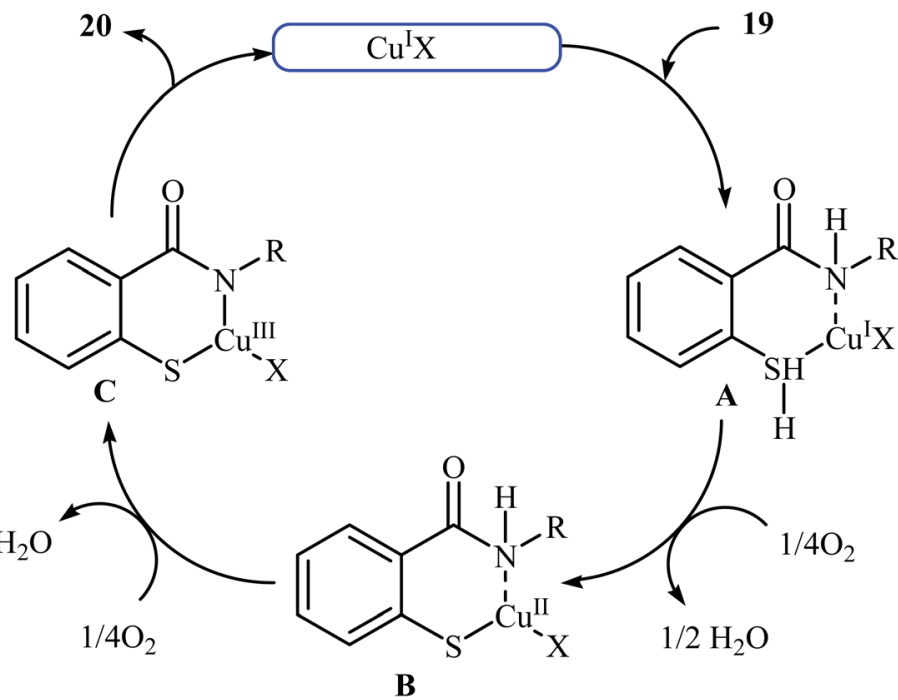

Scheme 11 Mechanistic proposal for the reactions in Scheme 9. 
<smiles>[R]SN([R])C([R])=O</smiles>
$\mathrm{O}_{2}, 100^{\circ} \mathrm{C}$

$\mathrm{TBD}=1,5,7$-triazabicyclo[4.4.0]dec-5-ene<smiles>[R]c1ccc(SN(C)C=O)cc1</smiles>

26a, $\mathrm{R}=\mathrm{Me}$; $(81 \%)$

26b, $\mathrm{R}=\mathrm{OMe} ;(85 \%)$

26c, $\mathrm{R}=\mathrm{F} ;(89 \%)$

26d, $\mathrm{R}=\mathrm{Cl} ;(83 \%)$

26e, $\mathrm{R}=\mathrm{Br}$; $(86 \%)$<smiles>[R]N([AsH2+])C(=O)O</smiles>

26j, R= H; (12\%)

26f, $\mathrm{R}=\mathrm{C}_{8} \mathrm{H}_{17} ;(75 \%)$

26g, $\mathrm{R}=\mathrm{CH}_{2} \mathrm{CH}_{2} \mathrm{OH}$; (56\%)

26h, $\mathrm{R}=\mathrm{CH}_{2} \mathrm{CH}_{2} \mathrm{Ph}$; $(90 \%)$

26i, $\mathrm{R}={ }^{c} \mathrm{Hex}$; (48\%)

26k, R= Et; $(78 \%)$

261, $\mathrm{R}=\mathrm{Bn} ;(72 \%)$

26m, R= ${ }^{c} \mathrm{Hex} ;(73 \%)$<smiles>O=C1CCCN1Sc1ccccc1</smiles>

26n, $\mathrm{n}=1 ;(92 \%)$

260, $\mathrm{n}=2 ;(97 \%)$

26p, $n=3 ;(94 \%)$<smiles>O=C1c2ccccc2C(=O)N1c1ccccc1</smiles>

26t, $(63 \%)$

Scheme $12 \mathrm{Cu}(\mathrm{I})$-catalyzed synthesis of $N$-formyl/acylsulfenamides 26 reported by Jang. ${ }^{25}$

$\mathrm{K}_{2} \mathrm{CO}_{3},{ }^{t} \mathrm{BuOK}, \mathrm{TBD}$, and DBU) were examined and the system $\mathrm{CuI} / \mathrm{TBD}$ was found to be optimal for this transformation. Various thiols 24 and secondary amides 25 were reacted well under the optimized reaction conditions to produce the corresponding $N$-carbonyl sulfonamides 26 in moderate to excellent yields (Scheme 12). However, this protocol for $N$-sulfenylation of primary amides was considerably less efficient. It is noted that this CuI-catalyzed reaction is equally efficient for both the aromatic and aliphatic thiols. A wide range of sensitive functional groups including ester, fluoro, chloro, bromo, alkoxy, and hyrdoxy are tolerated by the reaction conditions employed. This procedure offers scope for further manipulation of products. Mechanistic investigations revealed that the reaction starts with the generation of amide-CuI complex A via coordination of amide $\mathbf{2 5}$ to a copper ion, and then the reaction of intermediate A with in situ generated disulfide B from homocoupling of corresponding thiol $\mathbf{2 4}$ furnishes copper complex C. Subsequently, intermediate $\mathbf{C}$ undergoes reductive elimination to provide the expected sulfenamide 26 and generates PhS-CuI complex D. Finally, under aerobic oxidation conditions, PhS-

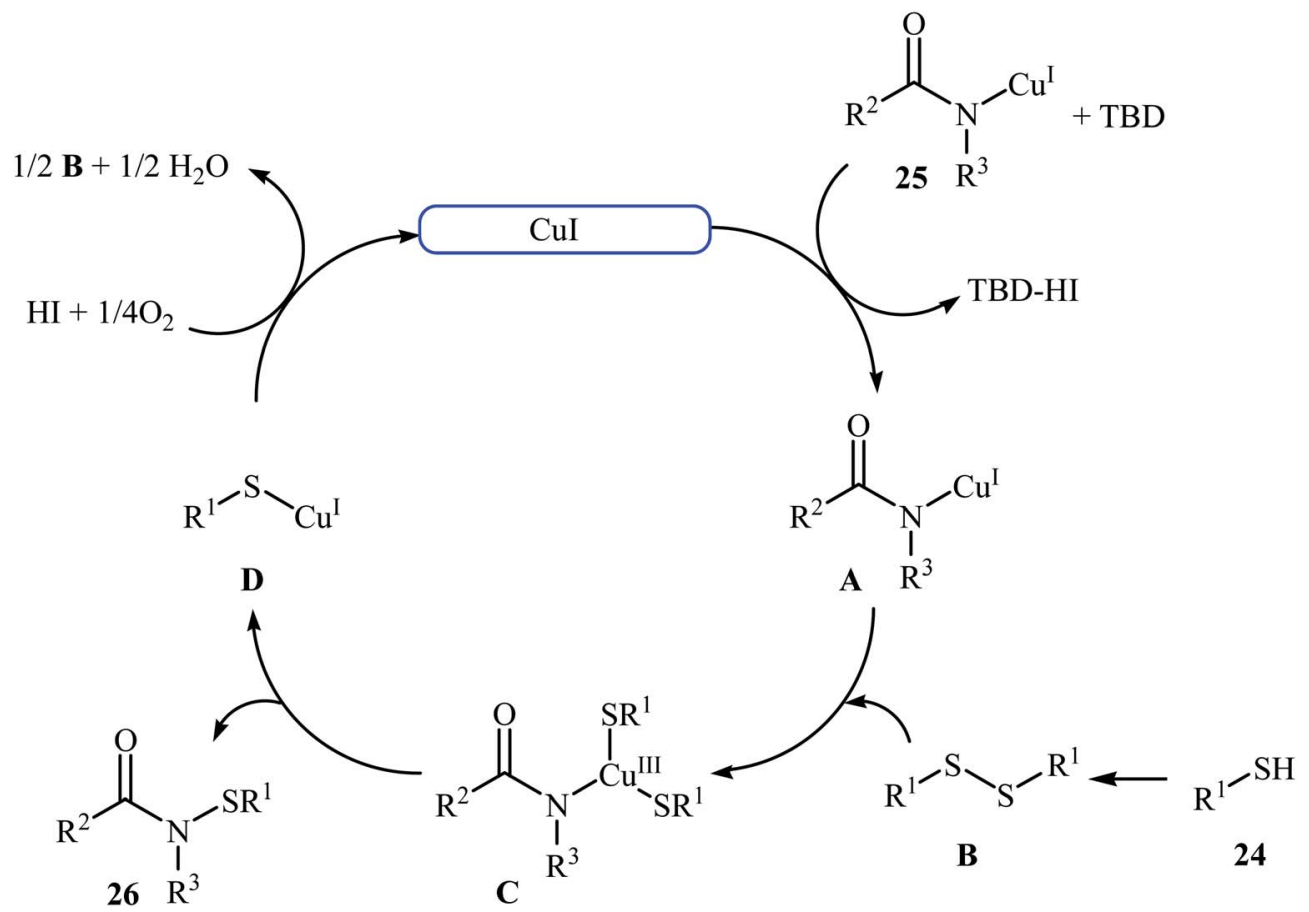

Scheme 13 Mechanistic proposal for the formation of 26 . 


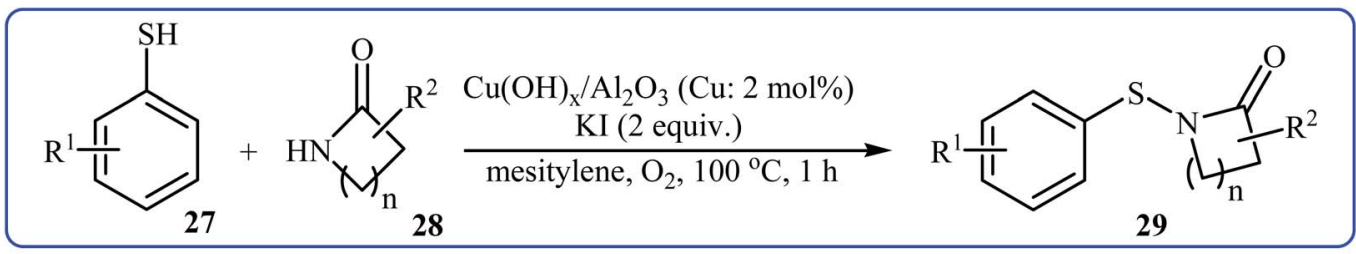

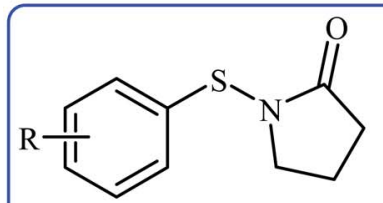

29a, R= H; (64\%)

29b, $\mathrm{R}=4-\mathrm{Me}$; $(80 \%)$

29c, $\mathrm{R}=3-\mathrm{Me} ;(74 \%)$

29d, R=2-Me; (63\%)

29e, $\mathrm{R}=4-\mathrm{OMe}$; $(86 \%)$

29f, $\mathrm{R}=4-\mathrm{Cl}$; $(81 \%)$<smiles>[R]CC(=O)N(CCC)Sc1ccc(C)cc1</smiles>

29g, R=3-Me; $(60 \%)$

29h, R= 5-Me; (39\%)

29i, R= 4- ${ }^{c}$ Hex; (>99\%)<smiles>Cc1ccc(SN2CCC2=O)cc1</smiles>

29j, $(32 \%)$<smiles>Cc1ccc(SN2CCN(C)C2=O)cc1</smiles>

Scheme 14 Sakagami's synthesis of $N$-acylsulfenamides 29

CuI complex $\mathbf{D}$ converts into a catalytically more reactive $\mathrm{CuI}$ complex and disulfide $\mathbf{B}$ (Scheme 13).

Recently, an efficient method for the synthesis of $N$-acylsulfenamides 29 via $\mathrm{Cu}$-catalyzed cross-coupling of aryl thiols 27 and lactams 28 has been developed by Sakagami and co-workers (Scheme 14). This intermolecular thiolation was achieved in mesitylene using a supported copper hydroxide catalyst $\mathrm{Cu}(\mathrm{OH})_{x} / \mathrm{Al}_{2} \mathrm{O}_{3}\left(\mathrm{Cu}: 2 \mathrm{~mol} \%\right.$ ) at $100{ }^{\circ} \mathrm{C}$ for $1 \mathrm{~h}$ under an oxygen atmosphere to afford $\mathrm{N}$-acylsulfenamides 3 in moderate to excellent yields. ${ }^{26}$

\section{Synthesis of sulfenylimines}

In 2015, Lee, Wang, and Jang developed an elegant Cu(I)-catalyzed oxidative cross-coupling reaction between thiols 30 and benzyl amines $\mathbf{3 1}$ for the construction of synthetically important
$N$-sulfenylimines 32 (Scheme 15). ${ }^{27}$ The best conversion efficiency was obtained for the reactions containing CuI ( 2 mol\%) and TBD (10 mol\%) in toluene at $100{ }^{\circ} \mathrm{C}$ under $\mathrm{O}_{2}$ atmosphere. This approach provides the first highly practical procedure for synthesizing $N$-sulfenylimines from commercially available and inexpensive thiols and amines. Functional groups including fluoro, chloro, and ether are tolerated by the reaction conditions employed. It is noteworthy that this $\mathrm{Cu}(\mathrm{I})$-catalyzed reaction is equally efficient for both the primary and secondary amines. According to the authors proposed mechanism, the reaction starts with the generation of an imine-Cu complex A via the aerobic oxidation of benzyl amine $\mathbf{3 1}$ by $\mathrm{Cu}$ catalyst. Meanwhile, homocoupling of starting thiol $\mathbf{3 0}$ affords disulfide intermediate $\mathbf{B}$. Finally, the reaction of complex $\mathbf{A}$ with disulfide $\mathbf{B}$ yields the expected $N$-sulfenylimines 32 (Scheme 16).

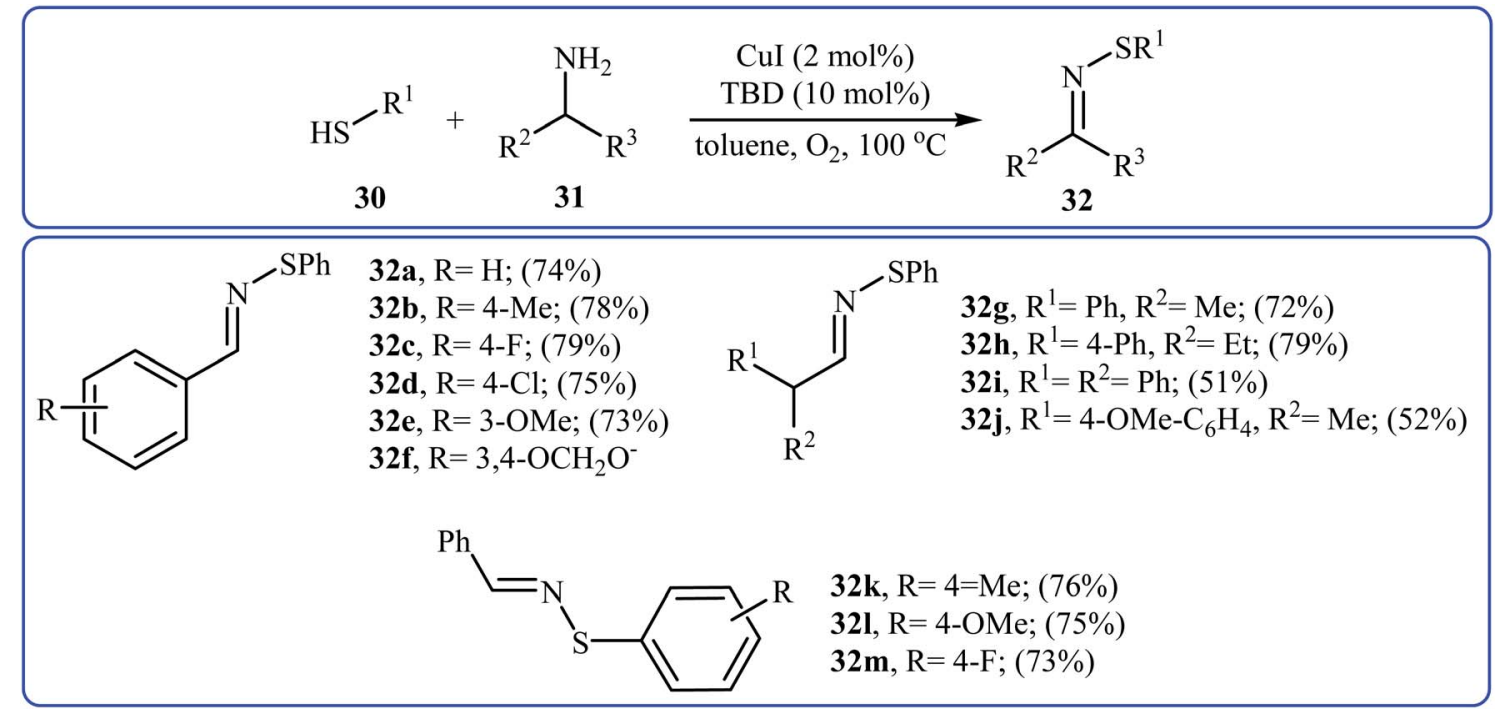

Scheme 15 Synthesis of $N$-sulfenylimines 32 from thiols 30 and benzyl amines 31 . 


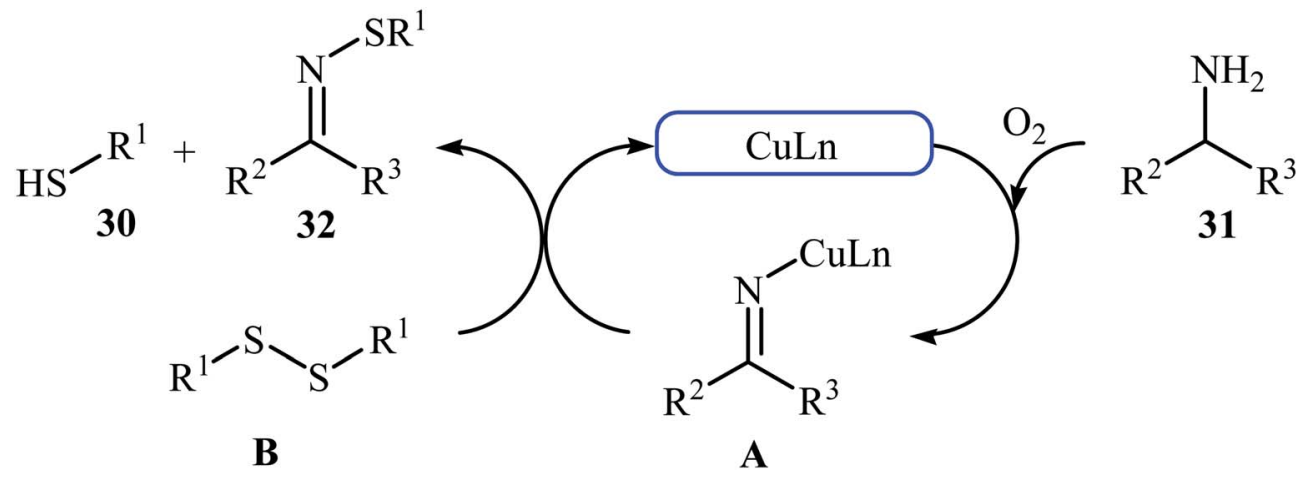

Scheme 16 Plausible mechanism for the formation of 32

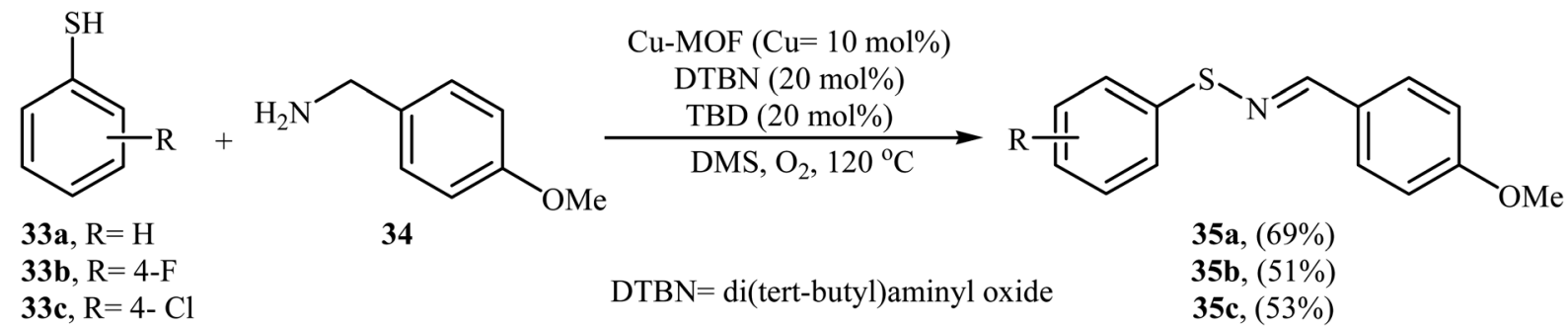

Scheme 17 Qiu-He's synthesis of N-sulfenylimines 35.

Shortly after this report, Qiu and He along with their coworkers showed that copper-based metal-organic frameworks with $p c u$-topology ( $p c u$-MOF) are efficient heterogeneous catalyst for the oxidative coupling of thiols and amines. Thus, by using $p c u$-MOF/DTBN/TBD as a catalytic system in DMSO under an $\mathrm{O}_{2}$ atmosphere, the coupling of thiophenols 33 with 3methoxybenzylamine $\mathbf{3 4}$ afforded corresponding $\mathrm{N}$-sulfenylimines 35 in moderate yields (Scheme 17). ${ }^{28}$

\section{Synthesis of sulfenylsulfoximines}

Very recently, Yang and co-workers showed that $N$-sulfenylsulfoximine derivatives $\mathbf{3 8}$ could be synthesized via dehydrocoupling reaction of thiols $\mathbf{3 6}$ with sulfoximines $\mathbf{3 7}$ in the presence of $1.0 \mathrm{~mol} \%$ of molecular iodine as the catalyst and 2.5 equiv. of $\mathrm{H}_{2} \mathrm{O}_{2}$ as an oxidant in eco-friendly polyethylene glycol400 (PEG-400) at $50^{\circ} \mathrm{C}$. Generally, target $N$-sulfenylsulfoximines were obtained in good to excellent yields (Scheme 18). ${ }^{29}$ The reaction showed excellent functional group tolerance, including fluoro, chloro, bromo, methoxy, and nitro groups that would allow further elaboration of the products. This $\mathrm{I}_{2}$-catalyzed reaction is applicable for both the (hetero)aromatic as well as benzylic thiols and for various substituted sulfoximines. It should be mentioned that the optimized reaction condition was also applied for the cross-dehydrogenative coupling reactions of thiophenol with a diverse set of functionalized anilines, and the reaction gave good yields of the expected sulfonamides. A possible mechanistic pathway was also proposed (Scheme 19), whereby the reaction is initiated with homocoupling of thiol $\mathbf{3 6}$ to give disulfide intermediate $\mathbf{A}$, which undergoes reaction with $\mathrm{I}_{2}$ affording sulfenyl iodide intermediate B. Subsequently, nucleophilic attack of sulfoximine 37 onto the activated S-I bond in intermediate $\mathbf{B}$ affords the cationic $N$-sulfenylsulfoximine $\mathbf{C}$, which by deprotonation convert to the desired products 38. The generated hydriodic acid is then oxidized by $\mathrm{H}_{2} \mathrm{O}_{2}$ to restore the catalyst $\mathrm{I}_{2}$, and water is the sole by-product. The

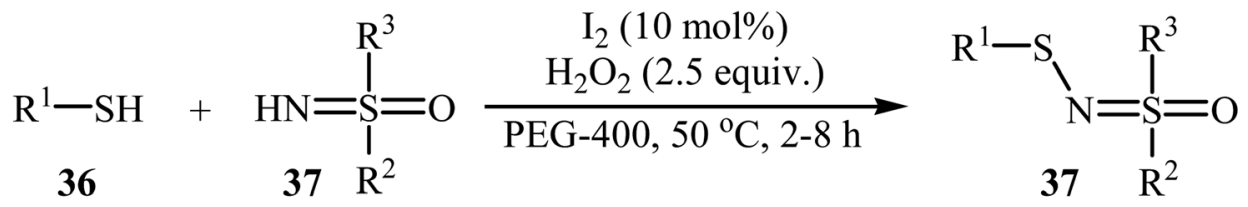

$$
\begin{aligned}
& \mathrm{R}^{1}=\text { aryl, heteroaryl, benzyl } \\
& \mathrm{R}^{2}=\text { aryl, alkyl, allyl } \\
& \mathrm{R}^{3}=\text { aryl }
\end{aligned}
$$




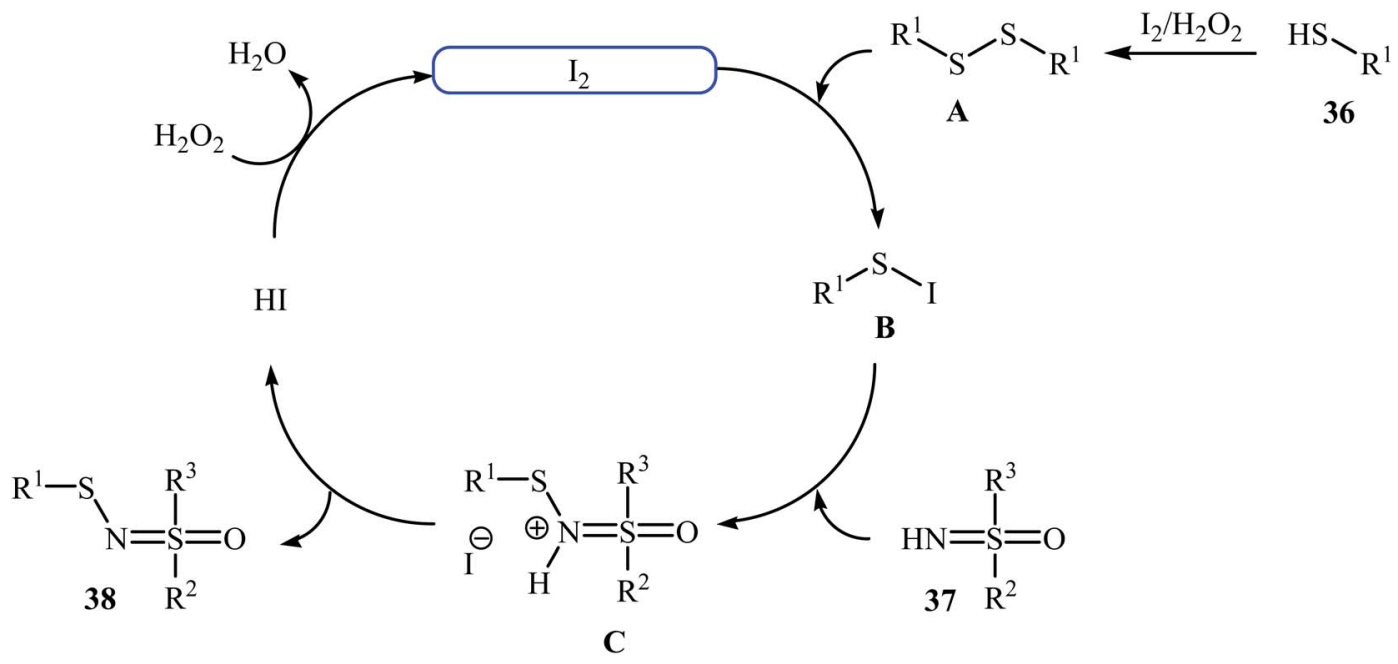

Scheme 19 Mechanistic proposal for the reaction in Scheme 18.

authors claimed that their report is the first example of the direct cross-dehydrogenative coupling reaction to construct $N$ sulfenylsulfoximines.

\section{Synthesis of sulfonamides}

Very recently, the Wei-Wang group have developed an efficient and straightforward approach for the synthesis of biologically important secondary and tertiary sulfonamides 41 via $\mathrm{I}_{2} \mathrm{O}_{5^{-}}$ mediated oxidative coupling of aryl thiols 39 and amines $\mathbf{4 0}$ (Scheme 20). ${ }^{30}$ The reaction was performed in acetonitrile at $60{ }^{\circ} \mathrm{C}$, tolerated various functional groups, and generally provided corresponding sulfonamides in moderate to high yields. It is noted that the reaction is applicable for various amines like aromatic, benzylic, and aliphatic amines. This protocol was also successfully applied to the preparation of gram quantities of the desired sulfonamide without sacrificing the yield or outcome of the methodology. The proposed reaction mechanism is outlined in Scheme 21 and comprises the following basic steps: (i) initial formation of disulfide $\mathbf{A}$ via dimerization of thiol 39; (ii) oxidation of disulfide $\mathbf{A}$ by $\mathrm{I}_{2} \mathrm{O}_{5}$ to give arylsulfonothioate $\mathbf{B}$ with the concomitant formation of molecular iodine; (iii) interaction of intermediate $\mathbf{B}$ with iodine to produce sulfonyl iodide $\mathbf{C}$; and (iv) nucleophilic substitution

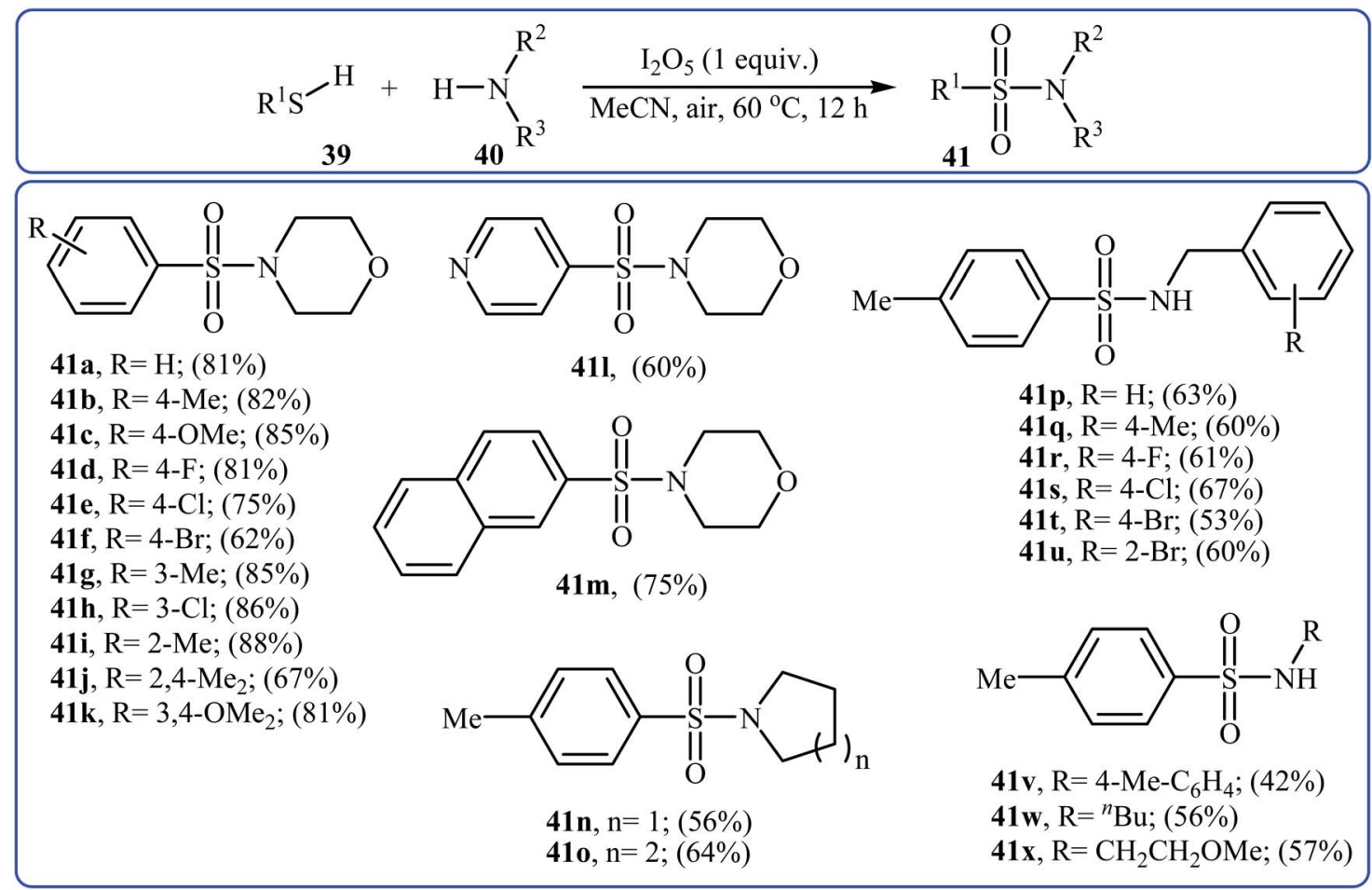

Scheme $20 \quad \mathrm{I}_{2} \mathrm{O}_{5}$-mediated direct construction of sulfonamides 41 from thiols 39 and amines 40 . 


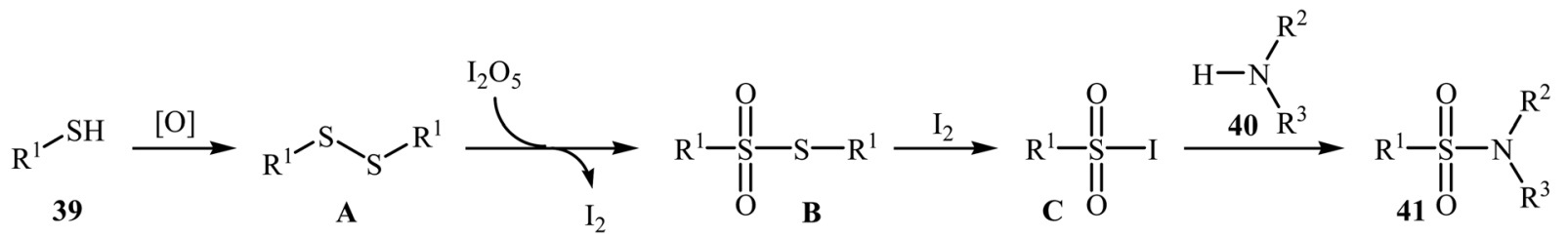

Scheme 21 Mechanism that accounts for the formation of sulfonamides 41 .

of sulfonyl iodide $\mathbf{C}$ by amine $\mathbf{4 0}$ and formation of the sulfonamide 41. To the best of our knowledge, this is the only example of direct construction of sulfonamides from readily-available thiols and amines reported so far.

\section{Outlook and conclusion}

Sulfur-nitrogen bond-containing compounds have extensive application in organic and medicinal chemistry. Synthetically, such organosulfur compounds are commonly prepared via crosscoupling of S-halo compounds and $\mathrm{N}-\mathrm{H}$ compounds or crosscoupling reactions between $\mathrm{N}$-halogenated compounds and thiols. However, the limited availability of commercial starting materials, the formation of undesired by-products and/or harsh reaction conditions are the main drawbacks of these methods. Recently, cross-dehydrogenative coupling reaction has become an attractive alternative to traditional $\mathrm{S}-\mathrm{N}$ cross-coupling reactions due to the waste-minimization and the costs associated with the preparation of starting materials. Shorter synthetic routes and high atom economy are the key features of these ecofriendly green reactions. This new page of sulfur-nitrogen bond formation has been successfully applied in the synthesis of a variety of S-N bond-containing compounds such as sulfenamides, sulfonamides, sulfenylimines, and sulfenyl-sulfoximines. Despite the significant achievements during the past few years in this interesting research arena, there are still many problems remained: (i) almost all of the catalysts and oxidants are limited to the use of copper and hypervalent iodine, respectively. Thus the exploration of different catalytic systems is highly desirable; (ii) the number of reported examples in some reactions such as synthesis of sulfonamides and sulfenylsulfoximines from $\mathrm{S}-\mathrm{H}$ and $\mathrm{N}-\mathrm{H}$ compounds are narrow and there is an urgent need to study the scope and limitations of these reactions; and (iii) other reactions such as coupling of thiols with urethanes and ureas should be explored. It is anticipated that the insight provided in this review will be beneficial for eliciting further research in this domain.

\section{Conflicts of interest}

There are no conflicts to declare.

\section{References}

1 R. J. W. Cremlyn, An introduction to organosulfur chemistry, John Wiley \& Sons Inc, New York, 1996.

2 N. Goncharov, A. N. Orekhov, N. Voitenko, A. Ukolov, R. Jenkins and P. Avdonin, in Nutraceuticals: Efficacy, Safety and Toxicity, ed. R. Gupta, Academic Press/Elsevier, Amsterdam, 2016, pp. 555-568.

3 C. T. Supuran, Nat. Rev. Drug Discovery, 2008, 7, 168-181.

4 S. Arshadi, E. Vessally, L. Edjlali, R. Hosseinzadeh-Khanmiri and E. Ghorbani-Kalhor, Beilstein J. Org. Chem., 2017, 13, 625-638.

5 J. Green, A. Troupin, L. Halpern, P. Friel and P. Kanarek, Epilepsia, 1974, 15, 329-349.

6 F. Engler, M. Maeder-Ingvar, E. Roulet and T. Deonna, Neuropediatrics, 2003, 34, 105-109.

7 (a) M. J. Brodie, A. Covanis, A. Gil-Nagel, H. Lerche, E. Perucca, G. J. Sills and H. S. White, Epilepsy Behav., 2011, 21, 331-341; (b) M. Abdoli, A. Angeli, M. Bozdag, F. Carta, A. Kakanejadifard, H. Saeidian and C. T. Supuran, J. Enzyme Inhib. Med. Chem., 2017, 32, 1071-1078.

8 (a) R. P. Shank, J. F. Gardocki, A. J. Streeter and B. E. Maryanoff, Epilepsia, 2000, 41, 3-9; (b) H. Saeidian and M. Abdoli, J. Sulfur Chem., 2015, 36, 463-470.

9 I. V. Koval', Russ. Chem. Rev., 1996, 65, 421-440.

10 Y. Zhu, M. R. Loso, G. B. Watson, T. C. Sparks, R. B. Rogers, J. X. Huang, B. C. Gerwick, J. M. Babcock, D. Kelley and V. B. Hegde, J. Agric. Food Chem., 2010, 59, 2950-2957.

11 (a) M. Behforouz and J. E. Kerwood, J. Org. Chem., 1969, 34, 51-55; (b) H. M. Gillis, L. Greene and A. Thompson, Synlett, 2009, 112-116; (c) H. Saeidian, M. Abdoli and Z. Mirjafary, Synthesis, 2015, 47, 1057-1075.

12 (a) L. Craine and M. Raban, Chem. Rev., 1989, 89, 689-712; (b) C. Bohnen and C. Bolm, Org. Lett., 2015, 17, 3011-3013.

13 For selected reviews on carbon-carbon cross-coupling reactions, see:(a) N. Miyaura and A. Suzuki, Chem. Rev., 1995, 95, 2457-2483; (b) F.-S. Han, Chem. Soc. Rev., 2013, 42, 5270-5298; (c) C. Valente, S. Çalimsiz, K. H. Hoi, D. Mallik, M. Sayah and M. G. Organ, Angew. Chem., Int. Ed., 2012, 51, 3314-3332.

14 For selected reviews on carbon-heteroatom cross-coupling reactions, see:(a) P. Ruiz-Castillo and S. L. Buchwald, Chem. Rev., 2016, 116, 12564-12649; (b) I. P. Beletskaya and V. P. Ananikov, Chem. Rev., 2011, 111, 1596-1636; (c) M. Abdoli, Z. Mirjafary, H. Saeidian and A. Kakanejadifard, RSC Adv., 2015, 5, 44371-44389; (d) K. Didehban, E. Vessally, A. Hosseinian, L. Edjlali and E. S. Khosroshahi, RSC Adv., 2018, 8, 291-301; (e) E. Vessally, K Didehban, R. Mohammadi, A. Hosseinian and M. Babazadeh, J. Sulfur Chem., 2018, DOI: 10.1080/17415993.2018.1436711.

15 For selected examples on heteroatom-heteroatom crosscoupling reactions, see:(a) Y. Zhou, S. Yin, Y. Gao, Y. Zhao, M. Goto and L. B. Han, Angew. Chem., Int. Ed., 2010, 49, 6852-6855; (b) W. He, X. Hou, X. Li, L. Song, Q. Yu and 
Z. Wang, Tetrahedron, 2017, 73, 3133-3138; (c) G. Wang, Q.-Y. Yu, S.-Y. Chen and X.-Q. Yu, Tetrahedron Lett., 2013, 54, 6230-6232; (d) C. Li, T. Chen and L.-B. Han, Dalton Trans., 2016, 45, 14893-14897.

16 For selected reviews on cross-dehydrogenative coupling reactions, see:(a) C. S. Yeung and V. M. Dong, Chem. Rev., 2011, 111, 1215-1292; (b) J. Yuan, C. Liu and A. Lei, ChemComm, 2015, 51, 1394-1409; (c) T. Chen, J.-S. Zhang and L.-B. Han, Dalton Trans., 2016, 45, 1843-1849.

17 (a) N. Taniguchi, Eur. J. Org. Chem., 2010, 2670-2673; (b) N. Taniguchi, Synlett, 2007, 1917-1920.

18 E. Rattanangkool, W. Krailat, T. Vilaivan, P. Phuwapraisirisan, M. Sukwattanasinitt and S. Wacharasindhu, Eur. J. Org. Chem., 2014, 4795-4804.

19 L. Yang, S. Li, Y. Dou, S. Zhen, H. Li, P. Zhang, B. Yuan and G. Yang, Asian J. Org. Chem., 2017, 6, 265-268.

20 Y. Dou, X. Huang, H. Wang, L. Yang, H. Li, B. Yuan and G. Yang, Green Chem., 2017, 19, 2491-2495.

21 A. Correa, I. Tellitu, E. Domínguez and R. SanMartin, Org. Lett., 2006, 8, 4811-4813.
22 R. Dahl, Y. Bravo, V. Sharma, M. Ichikawa, R.-P. Dhanya, M. Hedrick, B. Brown, J. Rascon, M. Vicchiarelli and A. Mangravita-Novo, J. Med. Chem., 2011, 54, 3661-3668.

23 Z. Wang, Y. Kuninobu and M. Kanai, J. Org. Chem., 2013, 78, 7337-7342.

24 T.-Q. Yu, Y.-S. Hou, Y. Jiang, W.-X. Xu, T. Shi, X. Wu, J.-C. Zhang, D. He and Z. Wang, Tetrahedron Lett., 2017, 58, 2084-2087.

25 C. Lee, Y. N. Lim and H. Y. Jang, Eur. J. Org. Chem., 2015, 5934-5938.

26 K. Sakagami, X. Jin, K. Suzuki, K. Yamaguchi and N. Mizuno, Chem. Lett., 2015, 45, 173-175.

27 C. Lee, X. Wang and H.-Y. Jang, Org. Lett., 2015, 17, 11301133.

28 W. Long, W. Qiu, C. Li, L. Song, G. Bai, G. Zhang and H. He, RSC Adv., 2016, 6, 40945-40952.

29 L. Yang, J. Feng, M. Qiao and Q. Zeng, Org. Chem. Front., 2018, 5, 24-28.

30 M. Zhu, W. Wei, D. Yang, H. Cui, L. Wang, G. Meng and H. Wang, Org. Biomol. Chem., 2017, 15, 4789-4793. 